\title{
DECLARACIÓN DE SAN JUAN EN LA XII EDICIÓN DE FELAIBE EN PUERTO RICO SAN JUAN, 15 DE ABRIL DE 2019
}

\begin{abstract}
Sandra Fábregas
Con la conferencia “Comunicación, Respeto y Diálogo”, a cargo del bioeticista Dr. Francisco León, radicado en Chile, se inauguró el XII Congreso de la Federación Latinoamericana y del Caribe de Instituciones de Bioética (FELAIBE), acto que se verificó el pasado 11 de abril de 2019 en la Universidad Interamericana de Puerto Rico. En el referido Congreso participaron más de 120 expertos y estudiosos de la Bioética y de las Comunicaciones, de los cuales alrededor de 60 provenían de Argentina, Brasil, Chile, Colombia, Costa Rica, Ecuador, España, Estados Unidos, México, Perú, República Dominicana y Venezuela. La presente edición del Congreso fue dedicada al Dr. León por su inspiradora actitud y hábil capacidad de gestión en su cargo como presidente de la Federación, y por su éxito en la promoción de la bioética en Latinoamérica. Este evento, de gran significación internacional, contó con la colaboración organizativa local del Centro Latino de Bioética y Humanidades (CELABIH) y de la Universidad Interamericana de Puerto Rico.
\end{abstract}

Se realizaron 16 mesas redondas, 12 sesiones de comunicaciones orales y una exhibición de afiches que fue particularmente auspiciada por la Fundación de Ciencias de Puerto Rico. En general, los temas tratados estuvieron enmarcados en uno de cinco módulos principales: Bioética Clínica, Investigación, Comunicación, Docencia y Bioética, y Desastres Naturales. Dentro de estos se atendieron temas de alto interés mediático como la marihuana medicinal y la edición genética, por ejemplo. Estos fueron atendidos por profesionales de la medicina, farmacia, enfermería, filosofía, derecho, teología, sociología, comunicaciones y psicología.

Dentro de los trabajos académicos se creó un espacio para presentar varios libros junto a sus autores.

La amplia y variada convocatoria tuvo como resultados un amplio diálogo interdisciplinario y la oportunidad de establecer redes de colaboración en las distintas temáticas que aborda la Bioética.

"Este congreso tuvo la particularidad de hacer un llamado a la acción, no solamente por los temas discutidos, sino por haber incorporado a buen número de expositores que integraron a sus ponencias el tema central del Congreso. Durante tres días los participantes tuvieron la oportunidad de establecer redes de colaboración con bioeticistas locales e internacionales", dijo Sandra M. Fábregas, presidenta del Congreso FELAIBE 2019.

La clausura de la jornada congresal contó con la conferencia: "La Bioética como proceso de comunicación hermenéutica", a cargo del Dr. Fernando Lolas Stepke, secretario general de la Asociación Mundial de Psiquiatría Social; además, se formalizó la incorporación de la Dra. Fábregas a la Academia Argentina de Ética en Medicina en calidad de miembro correspondiente extranjero, "por sus antecedentes de valor académico respecto de la bioética". El momento fue propicio para presentar la "Declaración de San Juan", acto a cargo del Dr. Rafael Burgos Calderón, profesor emérito de la Escuela de Medicina de Puerto Rico. Esta Declaración constituyó una excitativa en ocho puntos, entre los cuales destacan: (1) promover como prioridad la capacitación en el estudio de la bioética a los profesionales de la salud y a los comunicadores sociales; (2) mantener la comunicación continua y confiable en situaciones que comprometen los valores de salud y vida, y (3) promover un modelo eficiente de directrices anticipadas como un medio no solo para promover la autonomía de la persona, sino también un excelente cuidado médico. 
FELAIBE es la organización de bioética de más larga trayectoria en Latinoamérica. Fue fundada en 1991 con el objetivo principal de fomentar y mantener la mayor comunicación posible entre las instituciones de bioética de América Latina y del Caribe, el intercambio y la mutua ayuda en todo lo referente a iniciativas, actividades y proyectos ligados a la bioética.

El próximo Congreso de FELAIBE será en 2021, en Lima, Perú. La Asamblea de FELAIBE eligió como nuevo presidente al Dr. Jorge Ferrer, bioeticista reconocido tanto en Puerto Rico como en el extranjero. 